\title{
APLICACIONES TÉCNICAS Y CIENTÍFICAS DEL CAPITAL INTELECTUAL EN EL ACTUAL PROCESO CONTABLE DEL PERÚ
}

Dr. Emesto Augusto Polar Falcón*

\section{INTRODUCCIÓN}

En las últimas décadas se ha producido un cambio muy importante en relación con los factores generadores de beneficios en las empresas. Durante muchos años la economía se basó en la producción; bajo este paradigma los activos físicos constituyeron la principal fuente generadora de recursos. Actualmente, en cambio, estamos inmersos en una economia basada en el conocimiento, y ante esta nueva perspectiva, los activos intangibles cobran una inusitada relevancia en el proceso de creación de valor de las empresas. Mayor aún es el auge de los activos intangibles si se tiene en cuenta la revolución que se ha producido en materia de comunicaciones, lo que ha permitido a las empresas acceder al extraordinario poder que representa tener a su alcance la información adecuada en el momento preciso. Esto ha creado un nuevo ámbito para el mundo de los negocios y, como gran novedad, han aparecido las llamadas "empresas virtuales", en las cuales el activo "no se ve», pero las inversiones son grandes, y aun mayor es la posibilidad de generar recursos.

En el marco de esta nueva visión de la economía ha cobrado importancia una nueva expresión: "el capital intelectual" y pareciera que se trata de un nuevo elemento que se presenta como un desafío para la contabilidad tradicional. Ahora bien: ¿Se trata en realidad de un nuevo elemento que aparece en las empresas?, ¿por qué se afirma que es un desafío para la contabilidad tradicional?

\section{CONCEPTO DE CAPITAL INTELECTUAL}

Para responder a las interrogantes planteadas, es necesario, en primer lugar, intentar buscar una conceptualización de esta nueva expresión. Existe coincidencia en la doctrina en que el capital intelectual está compuesto por un conjunto de elementos de naturaleza inmaterial que son imprescindibles para el

* Docente Principal de la Facultad de Ciencias Contables y Director del Instituto de Investigación de Ciencias Financieras y Contables. Miembro del Comité Ejecutivo del Consejo Superior de Investigaciones-UNMSM, representante del Área Económico Empresarial 
desenvolvimiento de la empresa en un contexto como el actual basado en una economía del conocimiento.

\section{COMPONENTES DEL CAPITAL INTELECTUAL}

Se establecen los siguientes componentes del capital intelectual:

\section{A. Activos de mercado}

Comprenden marcas, denominación social de la empresa, fidelidad de la clientela, reserva de pedidos, canales de distribución, licencias y franquicias. En definitiva, son elementos que proporcionan a la empresa una ventaja competitiva en el mercado.

\section{B. Activos de propiedad intelectual}

Incluyen elementos como conocer a la empresa, secretos de fabricación, derechos de autor, patentes, derechos de diseño y marcas de fábrica y servicios.

\section{Activos de infraestructura}

Comprenden elementos que definen la forma de trabajo en la organización: filosofia de gestión, cultura corporativa, procesos de gestión, tecnologia de la información, sistemas de interconexión y relaciones financieras.

\section{Activos centrados en el individuo}

Incluyen elementos tales como nivel de estudios alcanzado, cualificaciones profesionales, conocimientos técnicos asociados con el trabajo, evaluación ocupacional, psicometria y competencias asociadas con el trabajo.
Estos elementos, a diferencia de los activos de mercado, de propiedad intelectual y de infraestructura, no pueden ser propiedad de la empresa.

El Estudio 7 del IFAC titulado "La medición y gerenciamiento del Capital Intelectual: una introducción", reconoce que los modelos desarrollados hasta el presente por la doctrina internacional coinciden en que el capital intelectual se puede conceptuar como la suma de tres componentes que se interrelacionan para la formación de valor:

1. El capital humano: Formado por las habilidades, educación, calificación personal, conocimientos relativos al trabajo, tasa ocupacional, tasa psicométrica, capacidades relacionadas con el trabajo, empuje empresarial, habilidades de acción y reacción para las innovaciones, flexibilidad, etc.

2. El capital clientela: Formado por las marcas de fábrica, los clientes, la lealtad de los clientes, los nombres de la empresa, la acumulación de pedidos, los canales de distribución, las colaboraciones de negocios, los acuerdos de licencias, los contratos favorables, los acuerdos de franchising, etc.

3. El capital organizacional (estructural). Dividido a la vez en:

a. Propiedad intelectual: conformado por patentes, derechos de edición, derechos de diseño, fórmulas secretas, marcas comerciales y marcas de servicios. 
b. Infraestructura de activos. Donde se considera la filosofia de gerenciamiento, la cultura corporativa, los proceso de gerenciamiento, los sistemas de información, los sistemas de redes de trabajo y las relaciones financieras.

Estos mismos elementos se refieren al capital humano como los recursos humanos y los temas que los afectan: relaciones entre la empresa y sus empleados, motivación en el trabajo, adhesión a la política y los objetivos globales de la compañía, formación, flexibilidad, en suma cuantos factores inciden en el funcionamiento eficaz de un equipo de personas. Con respecto al capital clientela, denominado capital relacional, expresa que es el que tiene que ver con la clientela, lealtad y satisfacción de los clientes, relaciones y acuerdos de distribución, franquicias, licencias, etc. Finalmente, el capital organizacional es definido como todo lo referente a los procesos y la tecnología, a cómo la organización convierte en rutina el conocimiento aportado por los empleados, a lo que queda dentro de la empresa cuando finaliza la jornada de trabajo y dichos empleados vuelven a sus casas y a la capacidad de la propia organización para innovar $y$ aprender.

Hasta ahora se ha intentado establecer qué elementos integran esta expresión que parece haberse puesto tan de moda en los últimos tiempos: "capital intelectual". Sin duda se trata de activos intangibles imprescindibles para la creación de valor en las empresas y que le otorgan a las mismas ventajas comparativas en relación con otras.

\section{NORMATIVIDAD VIGENTE}

Hoy, al haber cobrado los intangibles una mayor relevancia, se torna cada vez más imprescindible poseer información relativa a los mismos para la toma de decisiones.

En el marco de la normatividad vigente, tanto a nivel nacional como internacional no existe posibilidad de reconocimiento contable de estos activos intangibles autogenerados por la empresa.

Para que un recurso pueda ser reconocido contablemente como "Activo", el Marco de Conceptos del IASB, requiere que el mismo reúna los siguientes requisitos:

a. El bien debe brindar a la empresa, futuros beneficios que espera fluyan hacia la misma;

b. El acceso a los beneficios que produce debe estar bajo control de la empresa;

c. El control sobre los beneficios que produce el bien debe haberse originado en una transacción o hecho ocurrido con anterioridad;

d. La partida debe tener un costo o valor, que pueda ser medido en forma confiable.

La NIC 38 del IASB que define al activo intangible como "un activo identificable, de carácter no monetario y sin apariencia física, que se posee para ser utilizado en la producción o suministro de bienes y servicios, para ser arrendado a terceros o para funciones relacionadas con la administración de la entidad", 
establece que procede su reconocimiento contable si "a) Es probable que los beneficios económicos futuros que se han atribuido al mismo lleguen a la empresa, y b) $\mathrm{El}$ costo del activo puede ser medido de forma fiable".

En sintesis, de acuerdo con la norma internacional, para que un activo intangible sea reconocido contablemente, debe cumplir con los elementos de la definición de activos intangibles, esto es, identificabilidad, control sobre el recurso en cuestión y existencia de beneficios económicos futuros $y$, además, ser factible de cuantificar en forma razonable.

\section{DIFICULTADES DEL CAPITAL INTELECTUAL EN LA CONTABILIDAD FINANCIERA}

En razón de lo analizado varias son las dificultades para encuadrar a los intangibles en la contabilidad financiera.

La primera es la identificabilidad, ya que para el cumplimiento de este requisito será menester que la empresa pueda identificar los beneficios económicos que deriven de la misma.

El segundo inconveniente se refiere a la posibilidad de ejercer control sobre los beneficios que estos intangibles generan. En la NIC 38 , con respecto a este ítem se expresa: "Una empresa puede poseer un equipo de personas capaces, de manera que pueda identificar posibilidades de mejorar su nivel de competencia mediante la formación especializada, cuyo desembolso producirá beneficios económicos en el futuro. La empresa puede también esperar que dicho equipo continúe prestando sus servicios dentro de la entidad. Sin embargo, normalmente la empresa tendrá un control insuficiente sobre los beneficios futuros esperados que pueda producir un equipo de empleados con mayor especialización, como para poder considerar que los importes dedicados a la formación cumplen la definición de activos intangibles". Otro párrafo de la misma norma evidencia también la dificultad al expresar: "La empresa puede tener una cartera de clientes, o una determinada cuota de mercado, y esperar que, debido a los esfuerzos empleados en desarrollar relaciones y lealtad de los clientes, éstos vayan a continuar demandando los bienes y servicios ofrecidos por la empresa. Sin embargo, en ausencia de derechos legales $u$ otras formas de control, que protejan esta expectativa de relaciones, o de lealtad continuada por parte de los clientes, la empresa tendrá por lo general un grado de control insuficiente sobre los beneficios económicos que se podrian derivar de las mismas, como para poder considerar que tales partidas (cartera de clientes, cuotas de mercado, relaciones con la clientela, lealtad de los clientes) cumplen con la definición de activo intangible".

\section{PROPUEstas Planteadas}

Finalmente, y por lo general, no es posible distinguir entre los costos incurridos para la generación interna de estos intangibles, de los necesarios para el mantenimiento de las funciones operativas, por lo que es bastante difícil lograr medir objetivamente el valor de los mismos en la empresa. 
Sin embargo, y ante la necesidad de contar con información sobre los intangibles, tanto la doctrina como algunos grupos de empresarios han hecho distintas propuestas para considerar de alguna manera a estos elementos generadores de contribución marginal.

Algunas de estas propuestas intentan incluir a los intangibles autogenerados dentro de los estados financieros, esforzándose por adaptar los mismos al marco conceptual de los estados financieros. Así, se proponen analizar uno por uno los factores que acuerdan ventajas comparativas a la empresa y que no están registrados en ningún otro activo, a efectos de segregar la porción de los mismos atribuible a ingresos futuros, para proceder a su activación como parte del costo del valor autogenerado. Otros autores creen que deberian reformularse los principios contables para que el reconocimiento de los intangibles pudiera tener cabida en ellos.

Otras propuestas, en cambio, intentan superar las limitaciones inherentes al sistema contable mediante el uso de información no financiera que les permita conocer mejor la situación de la empresa, aunque existe gran controversia en relación con el modo de abordar el tema.

La labor recién comienza, la contabilidad se enfrenta ante el gran desafio de establecer normas que permitan homogeneizar los criterios empleados para la identificación, medición y presentación de los activos intangibles a fin de que los usuarios puedan contar con información confiable para la toma de decisiones.
VI. LA IMPORTANCIA DEL CAPITAL INTELECTUAL EN LA XXIV CONFERENCIA INTERAMERICANA DE CONTABILIDAD

El Área 1.Investigación Contable concentra en estos eventos interamericanos bianuales a contadores públicos dedicados a la investigación de la ciencia contable. En este último evento el Área 1Investigación Contable, presentó el Tema 1.1 La información financiera frente al desafio de nuevos usuarios con la exposición de cuatro excelentes trabajos nacionales.

Por primera vez en esta Área, se ha presentado el Sub Tema 1.1.1. Capital Intelectual, con la exposición de tres trabajos nacionales.

El trabajo nacional mảs interesante fue: El capital intelectualanálisis critico en el marco de las nuevas necesidades, presentado por tres contadores públicos uruguayos, que se hicieron acreedores al Segundo Premio de la Conferencia Interamericana y a merecidos elogios al contenido del trabajo expuesto de doce páginas, por la profundidad de conceptos, criterios, insertaciones de acertados párrafos de diversos autores, cuadros analiticos y precisiones sobre el capital intelectual.

Los titulos de este trabajo nacional son los siguientes:

Capitulo I Introducción

- La creación de valor en las empresas en la nueva economía.

CapituloII El debate sobre el cumplimiento de los objetivos de los estados contables y su utilidad. 
Capitulo III Creación y desarrollo de activos intangibles: El capital intelectual

- Las fuentes de creación de valor: el capital intelectual

- Definiciones de capital intelectual. Conceptualización. En la búsqueda de un concepto aceptado umversalmente.

Principales activos intangibles definidos por la corriente de capital intelectual

- Modelos de medición del capital Intelectual

- Modelos de medición de capital intelectual de Karl Sveiby: el monitor de activos intangibles

- Propuestas tradicionales para medir la creación de valor

Capitulo IV. La visión de la profesión

1. ¿Los estados contables o sus notas revelan todos los hechos pasados que puedan indicar la existencia de una fuente generadora de valor?

2. ¿Los estados contables consideran la influencia de las actividades desarrolladas dentro de las empresas como fuente generadora de valor?

- Identificabilidad

- Control

- Beneficios económicos futuros

3. ¿La profesión contable permite la valorización de aquellos activos intangibles de reconocimiento admitido siguiendo criterios de medición alineados con la cuantificación de su potencialidad como fuente de generación de valor?
4. ¿Permiten los estados contables extraer conclusiones válidas sobre la evolución económica y financiera de las empresas basadas en una razonable correlación entre los ingresos y gastos asociados a la utilización del capital intelectual?

CapituloV. Nuestra propuesta: Modelo de información complementaria sobre capital intelectual

\section{Capítulo VI Guia de discusión}

\section{Capitulo VII Conclusiones}

1. Necesidad de incorporar información sobre el capital intelectual

2. Sobre el futuro de la profesión

3. Cambios a las normas contables

\section{Bibliografia}

\section{CAPITAL INTELECTUAL-INFOR- MACIÓN COMPLEMENTARIA A LOS ESTADOS CONTABLES}

El capítulo $\mathrm{V}$ del mencionado trabajo nacional interamericano presenta el formulario titulado: "Capital intelectual-información complementaria a los estados contables", como una excelente aportación al desarrollo de la información contable, que merece los siguientes comentarios sobre su estructura y contenido:

1. Es la primera vez que los contadores públicos tenemos la posibilidad de brindar a la empresa una información 
cuantitativa y cualitativa complementaria sobre capital intelectual, debidamente interconectada con indicadores con base contable y extracontable. Esta interconexión es logro inobjetable que otorga un gran mérito al cuadro diseñado.

2. Los componentes del capital intelectual están expuestos en tres categorias: Mercado; Innovación $y$ tecnología; $y$ Competencias del personal.

En cada categoria se observan columnas de unidad de medida, base contable, base extracontable y base mixta. Estas tres últimas columnas comparativas de un año a otro, lo que le da al cuadro un valor agregado para efectuar análisis y evaluaciones de carácter financiero y económico.

3. Estamos, por lo tanto, frente a una nueva era de información contable y extracontable, que nace en el continente americano. Debemos considerar esta información complementaria como la primera puerta que se abre en el conglomerado de conceptos, criterios y análisis teóricos que están rodeando a los temas de capital intelectual y contabilidad del conocimiento.

4. El mencionado formulario se muestra en el anexo N. ${ }^{\circ} 1$ y está sujeto a un exhaustivo análisis de los componentes expuestos en las tres categorías. Sin duda alguna, su contenido es novedoso y despierta muchas inquietudes profesionales y campos propicios para mayores estudios de investigación.
VIII.ENCUESTAS APLICADAS AL USO DEL FORMULARIO DE: "CAPITAL INTELECTUALINFORMACIÓN COMPLEMENTARIA A LOS ESTADOS CONTABLES"

En cumplimiento de uno de los objetivos del estudio de investigación, se distribuyó en el segundo semestre del 2003, a 100 contadores públicos, el siguiente Cuestionario de Investigación 2003, cuyo contenido dice:

\section{CUESTIONARIO DE INVESTIGACIÓN 2003 CAPITAL INTELECTUAL \\ INFORMACIÓN COMPLEMENTARIA A LOS ESTADOS CONTABLES \\ AL 31 DE DICIEMBRE DEL 2002}

1. En el Área de "Investigación Contable"Sub. Tema 1.1.1. Capital Intelectual, tres contadores públicos de la República Oriental del Uruguay presentaron en la XXIV Conferencia Interamericana de Contabilidad un excelente trabajo nacional titulado: «El Capital IntelectualAnálisis Crítico en el marco de las nuevas necesidades de información para los usuarios de información financieran.

2. En este trabajo nacional, se incluye el formulario: "Capital intelectualInformación complementaria a los estados contables" en el que sólo se han colocado dos columnas de Base Contable-2002 y Base Extracontable2002; la primera columna para mostrar información contable al cierre 2002 procedente de los libros de la empresa, en la medida que se puedan obtener: y lo más importante, la segunda columna para anotar la información extracontable, al cierre 2002 , de aquellos rubros que se consideren que la empresa los tiene, los 
tendrá o puede autogenerarlos basándose en el futuro de sus actividades o cambios que sean indispensables para lograr el desarrollo y la prosperidad de la empresa.

3. Su información es confidencial, pues no tiene que anotar el nombre de la empresa; sirvase devolverla al investigador que le ha pedido su colaboración antes del martes $02 \mathrm{de}$ setiembre del 2003, fecha en que el investigador tiene que presentar el informe final de sus encuestas.

Muchas Gracias. La Comisión de Investigación

El formulario adjunto al "Cuestionario de Investigación 2003", que se muestra en el Anexo N. ${ }^{\circ} 2$, contiene solamente la "Base Contable Año 2002", y la "Base Extracontable Año 2002", sin buscar la comparabilidad con el año anterior 2001, con la finalidad de simplificar el proceso de las encuestas y facilitar un rápido retorno de los formularios con la información solicitada.

Como resultado de las encuestas, se recibieron 80 formularios con datos contables y extracontables del año 2002. Se incluye en el presente informe del estudio de investigación un formulario de datos recibidos que se muestra en el Anexo N. 3 con respectivas notas aclaratorias, dadas por un contador público peruano, verdaderamente preocupado por el tema.

El análisis de los otros 79 formularios recibidos revela 10 siguiente:

1. La mayoria de los contadores públicos llenaron con buena información la columna "Base
Contable-Año 2002"; pero la información de la columna "Base Extracontable-Año 2002" es reducida.

2. Esta información reducida proporcionada por 79 contadores públicos, demuestra que no tienen un conocimiento cabal de los procesos del capital intelectual.

3. Otra causa de esta información reducida de la columna "Base Extracontable-Año 2002", podría ser producto de la formación universitaria sobre contabilidad tradicional, que se sustenta en los libros y documentos de la empresa, lo que los inhibe a proyectarse en dar información extracontable proveniente de otras fuentes.

4. Por último, una minoría de contadores públicos no colocó información alguna en la columna "Base ExtracontableAño 2002", lo que confirma un desconocimiento casi total de los procesos del capital intelectual.

\section{CONCLUSIONES}

1. La bibliografía, separatas y artículos de revistas especializadas, provenientes de otros países con avanzada tecnologia contable, confirma que los estudios sobre capital intelectual tienen un notable avance; mientras que en el Perú no se ha planificado una adecuada difusión a base de seminarios, fórums, conferencias, etc.; ni se han publicado libros con el tema del capital intelectual aplicado a realidades de entorno empresarial nacional. 
2. Indudablemente que a nivel internacional se está avanzando en información adicional sobre el capital intelectual, dada la inquietud permanente en el ámbito de los contadores públicos de buscar los caminos que permiten cuantificar los datos obtenidos de la empresa, para presentarlos como información necesaria para la toma de decisiones sobre los componentes del capital intelectual. En el Perú no hay interés aún para estudiar tales componentes ni para buscar la cuantificación como elemento necesario informativo.

3. Al realizar las aplicaciones prácticas de capital intelectual, tal como se ha demostrado con el "Cuestionario de Investigación 2003", la revelación de datos extracontables 2002 de escaso contenido informativo, demuestra que no se adiciona ninguna información de capital intelectual en los estados financieros tradicionales que preparan los contadores públicos en el Perú.

\section{RECOMENDACIONES}

1. Es un deber para los contadores públicos $y$ estudiantes universitarios de todas las facultades del Sistema de la Universidad Peruana, exigir el dictado de cursos, conferencias y seminarios sobre capital intelectual, tanto a los colegios profesionales como a sus propias universidades, para asimilar las innovaciones contables y extracontables que se están presentando. Así, los contadores públicos del perú estarán capacitados en ofrecer nuevos servicios profesionales competitivos, aportando planteamientos de información contable de avanzada. De igual forma, los estudiantes universitarios, futuros contadores públicos, al salir de la universidad tendrán una adecuada preparación sobre este interesante tema profesional y estarán preparados para enfrentarse al reto de información futura que exigirán las empresas que hayan captado la importancia de recibir información contable sobre capital intelectual.

2. También tiene prioridad conocer los avances logrados sobre capital intelectual, realizando serios estudios de los trabajos nacionales que tratan este tema; y de los artículos y libros que difunden los alcances logrados en las aplicaciones contables $y$ extracontables a nivel empresarial.

3. El reto más ambicioso será buscar la mejor aplicación del capital intelectual en la economia peruana, para producir mayor información confiable en los estados financieros que preparen los contadores públicos, que permita el progreso $y$ crecimiento financiero $y$ económico de las empresas del Perú, el incremento de puestos de trabajo y la mejora de los niveles económicos de la población peruana. 
ANEXO N. ${ }^{\circ} 1$

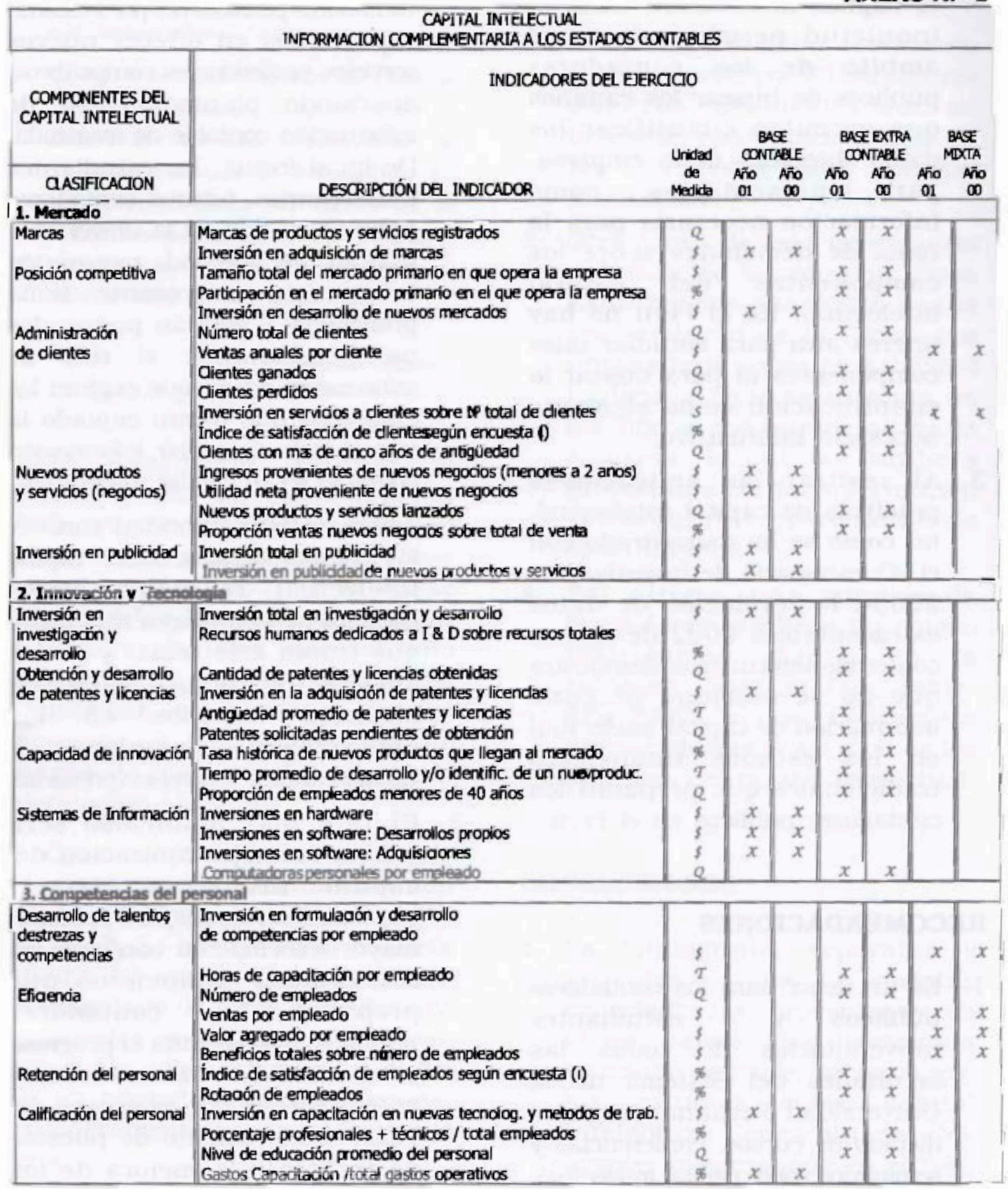


ANEXO N.O 2

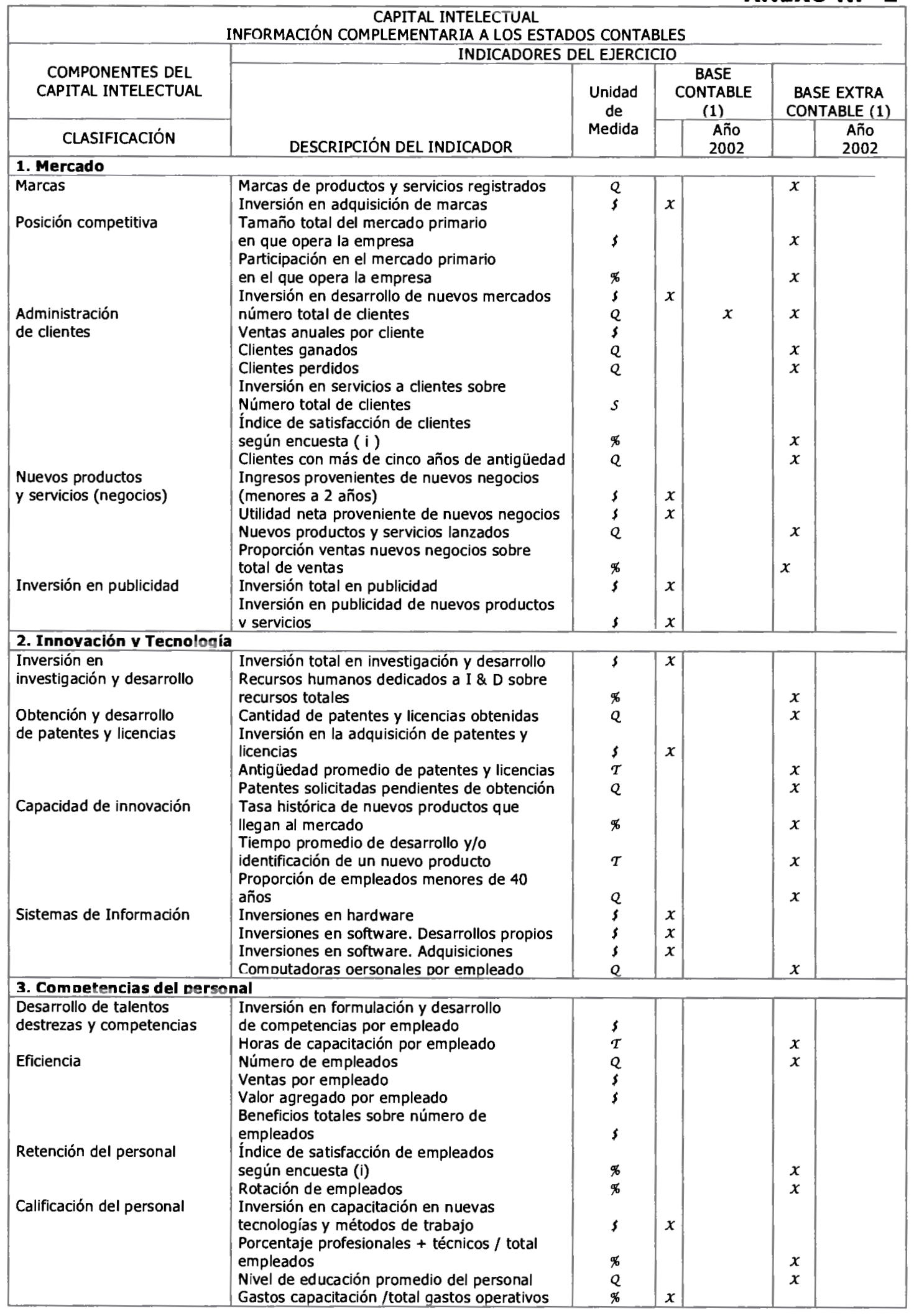

Referencia sobre la unidad de medida: $\mathcal{T}$ Tiempo; $\%$ Torcentaje; Q Cantidad; $\$$ Importe; (i), Incorporar ficha técrica de las encuestas realizadas. las marcas ' $X$ ' sirven para indicar los rubros que solicitan información 
ANEXO N.O

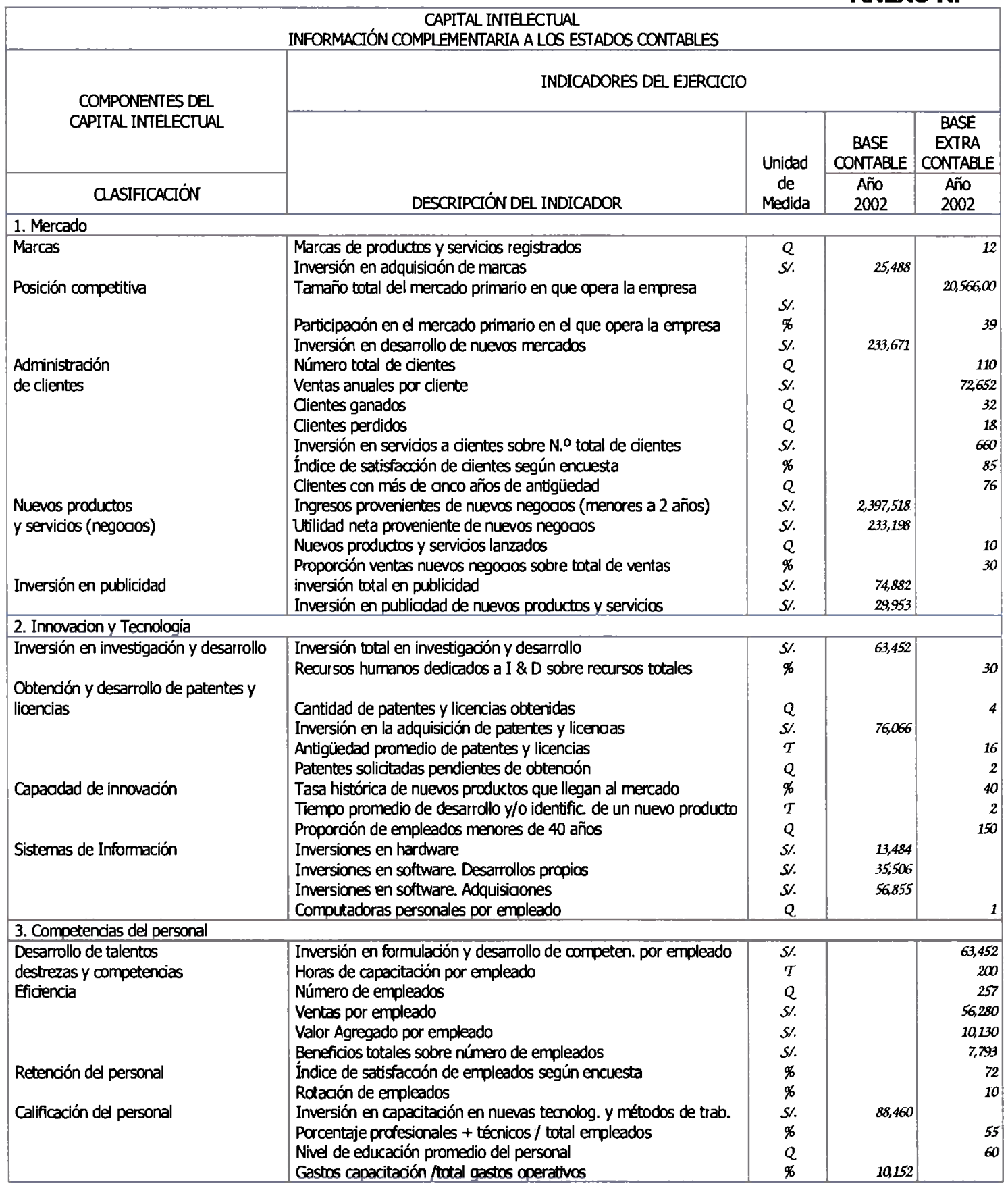


EXPLICACIONES ADICIONALES AL ANEXO N.०3

BASE

CONTABLE

2002

\begin{tabular}{|c|c|c|c|}
\hline \multirow{2}{*}{\multicolumn{4}{|c|}{ 1. Mercados }} \\
\hline & & & \\
\hline \multirow[t]{2}{*}{ Marcas } & $\begin{array}{l}\text { Marcas de productos y } \\
\text { servicios registrados }\end{array}$ & & $\begin{array}{l}\text { Se hizo un estudio de los modelos clásicos } \\
\text { de confección, en el segmento Damas, } \\
\text { caballeros y niños, producto del estudio, } \\
\text { existe la posibilidad de introducir al } \\
\text { mercado } 12 \text { marcas de ropa sport. } \\
\end{array}$ \\
\hline & $\begin{array}{l}\text { Inversión en } \\
\text { adquisición de marcas }\end{array}$ & $\begin{array}{l}\text { Durante el presente año se invirtieron } S / .25,488 \\
\text { en la adquisición de } 2 \text { marcas de prendas de } \\
\text { vestir. }\end{array}$ & \\
\hline \multirow{3}{*}{$\begin{array}{l}\text { Posición } \\
\text { competitiva }\end{array}$} & $\begin{array}{l}\text { Tamaño total del } \\
\text { mercado primario } \\
\text { en que opera la } \\
\text { empresa }\end{array}$ & & $\begin{array}{l}\text { Se estima que el volumen de ventas en el } \\
\text { país asciende a } \$ / .20566,000 \text {. }\end{array}$ \\
\hline & $\begin{array}{l}\text { Participación en el } \\
\text { mercado primario } \\
\text { en el que opera la } \\
\text { empresa }\end{array}$ & & $\begin{array}{l}\text { La empresa ocupa el } 39 \% \text { de las ventas en } \\
\text { el país. }\end{array}$ \\
\hline & $\begin{array}{l}\text { Inversión en desarrollo } \\
\text { de nuevos mercados }\end{array}$ & $\begin{array}{l}\text { Se invirtió un total de } S / .233,671 \text { en la apertura } \\
\text { de sucursales en las ciudades de Tacna, Ica y } \\
\text { Arequipa. }\end{array}$ & \\
\hline \multirow{7}{*}{$\begin{array}{l}\text { Administración } \\
\text { de clientes }\end{array}$} & $\begin{array}{l}\text { Número total de } \\
\text { clientes }\end{array}$ & & $\begin{array}{l}\text { Se estima aumentar el potencial de clientes } \\
\text { a } 110 \text {. }\end{array}$ \\
\hline & $\begin{array}{l}\text { Ventas anuales por } \\
\text { cliente }\end{array}$ & & $\begin{array}{l}\text { El promedio de ventas anuales por cliente } \\
\text { es de } S / .72,652 \text {. }\end{array}$ \\
\hline & Clientes ganados & & $\begin{array}{l}\text { El número de clientes nuevos durante el } \\
\text { año fue de } 32 \text {. }\end{array}$ \\
\hline & Clientes perdidos & & $\begin{array}{l}\text { Se perdieron } 18 \text { clientes, debido a la } \\
\text { descontinuación de } 6 \text { tipos de prendas de } \\
\text { vestir. }\end{array}$ \\
\hline & $\begin{array}{l}\text { Inversión en servicios } \\
\text { a clientes sobre N. } \\
\text { total de clientes }\end{array}$ & & $\begin{array}{l}\text { La relación de inversión en servicios al } \\
\text { cliente es de } 660 \text {, razón por la cual } \\
\text { estamos trabajando para mejorar la calidad } \\
\text { del servicio. }\end{array}$ \\
\hline & $\begin{array}{l}\text { Indice de satisfacción } \\
\text { de clientes según } \\
\text { encuesta }\end{array}$ & & $\begin{array}{l}\text { El } 85 \% \text { de la clientela está satisfecho del } \\
\text { servicio y la puntualidad en la entrega de } \\
\text { sus requerimientos. }\end{array}$ \\
\hline & $\begin{array}{l}\text { Clientes con más de } \\
\text { cinco años de } \\
\text { antigüedad }\end{array}$ & & $\begin{array}{l}\text { La empresa cuenta con una clientela } \\
\text { cautiva de } 76 \text {. }\end{array}$ \\
\hline \multirow{6}{*}{$\begin{array}{l}\text { Nuevos } \\
\text { productos } \\
\text { y servicios } \\
\text { (negocios) }\end{array}$} & $\begin{array}{l}\text { Ingresos provenientes } \\
\text { de nuevos negocios } \\
\text { (menores de } 2 \text { años) }\end{array}$ & $\begin{array}{l}\text { Se obtuvo en el año } S / .2^{\prime} 397,518 \text {, por concepto } \\
\text { de apertura de tiendas en épocas de fiestas. }\end{array}$ & \\
\hline & $\begin{array}{l}\text { Utilidad neta } \\
\text { proveniente de nuevos } \\
\text { negocios }\end{array}$ & $\begin{array}{l}\text { La utilidad neta por apertura de nuevos negocios } \\
\text { fue de } 233,198 \text {. }\end{array}$ & \\
\hline & $\begin{array}{l}\text { Nuevos productos y } \\
\text { servicios lanzados }\end{array}$ & & $\begin{array}{l}\text { Hay un proyecto de lanzamiento de } 10 \\
\text { tipos de prendas para damas. }\end{array}$ \\
\hline & \begin{tabular}{|l|} 
Proporción ventas \\
nuevos negocios sobre \\
total ventas
\end{tabular} & & $\begin{array}{l}\text { La proporción de ventas en nuevos } \\
\text { negocios fue de } 30\end{array}$ \\
\hline & $\begin{array}{l}\text { Inversión total en } \\
\text { publicidad }\end{array}$ & \multicolumn{2}{|l|}{ Se invirtieron $S / .74,882$ en publicidad y promociones } \\
\hline & $\begin{array}{l}\text { Inversión en publicidad } \\
\text { de nuevos productos y } \\
\text { servicios }\end{array}$ & $\begin{array}{l}\text { Se invirtieron } \$ / .29,953 \text { en el lanzamiento de } \\
\text { nuevos productos a nivel nacional }\end{array}$ & \\
\hline
\end{tabular}

BASE EXTRA

CONTABLE

2002 


\begin{tabular}{|c|c|c|c|}
\hline & & $\begin{array}{c}\text { BASE } \\
\text { CONTABLE }\end{array}$ & $\begin{array}{l}\text { BASE EXTRA } \\
\text { CONTABLE }\end{array}$ \\
\hline & & 2002 & 2002 \\
\hline 2. Innovación & Tecnología & & \\
\hline Inversión en & $\begin{array}{l}\text { Inversión total en } \\
\text { investigación y } \\
\text { desarrollo }\end{array}$ & $\begin{array}{l}\text { Se enviarón al extranjero algunos trabajadores } \\
\text { por } S / .63,452\end{array}$ & \\
\hline $\begin{array}{l}\text { desarrollo } \\
\text { destion y }\end{array}$ & \begin{tabular}{|l|} 
Recursos humanos \\
dedicados a I \& D \\
sobre recursos totales \\
\end{tabular} & & $\begin{array}{l}\text { La empresa cuenta con } 30 \text { trabajadores } \\
\text { dedicados a la investigación. }\end{array}$ \\
\hline & $\begin{array}{l}\text { Cantidad de patentes y } \\
\text { licencias obtenidas }\end{array}$ & & Se obtuvo un total de 4 patentes. \\
\hline Obtención y & $\begin{array}{l}\text { Inversión en la } \\
\text { adquisición de } \\
\text { patentes y licencias }\end{array}$ & E gasto fue de 76,066 & \\
\hline $\begin{array}{l}\text { desarrollo } \\
\text { de patentes y }\end{array}$ & $\begin{array}{l}\text { Antigüedad promedio } \\
\text { de patentes y licencias }\end{array}$ & & La antigüedad promedio es de 16 años. \\
\hline licencias & $\begin{array}{l}\text { Patentes solicitadas } \\
\text { pendientes de } \\
\text { obtención }\end{array}$ & & $\begin{array}{l}\text { A la fecha se encuentran en trámite } 2 \\
\text { licencias extranjeras. }\end{array}$ \\
\hline & $\begin{array}{l}\text { Tasa histórica de } \\
\text { nuevos productos que } \\
\text { lleqan al mercado } \\
\end{array}$ & & $\begin{array}{l}\text { Actualmente hay } 40 \text { productos en el } \\
\text { mercado. }\end{array}$ \\
\hline $\begin{array}{l}\text { Capacidad de } \\
\text { innovación }\end{array}$ & $\begin{array}{l}\text { Tiempo promedio de } \\
\text { desarrollo y/o } \\
\text { identificación de un } \\
\text { nuevo producto } \\
\end{array}$ & & $\begin{array}{l}\text { El tiempo promedio para desarrollar un } \\
\text { nuevo producto es de } 2 \text { por mes. }\end{array}$ \\
\hline & $\begin{array}{l}\text { Proporción de } \\
\text { empleados menores de } \\
40 \text { años }\end{array}$ & & $\begin{array}{l}\text { Los empleados menores de } 40 \text { años } \\
\text { asciende a } 150\end{array}$ \\
\hline $\begin{array}{l}\text { Sistemas de } \\
\text { Información }\end{array}$ & $\begin{array}{l}\text { Inversiones en } \\
\text { hardware }\end{array}$ & Se adquirieron nuevas computadoras por 13,484 & \\
\hline & $\begin{array}{l}\text { Inversiones en } \\
\text { software: Desarrollos } \\
\text { propios }\end{array}$ & $\begin{array}{l}\text { El gasto total en desarrollo de nuevos } \\
\text { programas fue de } 35,506 \text {. }\end{array}$ & \\
\hline & $\begin{array}{l}\text { Inversiones en } \\
\text { software: } \\
\text { Adquisiciones }\end{array}$ & $\begin{array}{l}\text { La inversión en adquisición de nuevos software } \\
\text { fue de } 56,855\end{array}$ & \\
\hline & $\begin{array}{l}\text { Computadoras } \\
\text { personales por } \\
\text { empleado }\end{array}$ & & $\begin{array}{l}\text { La empresa cuenta con tecnología de } \\
\text { última generación. }\end{array}$ \\
\hline 3. Combetencias & del Dersonal & & \\
\hline $\begin{array}{l}\text { Desarrollo de } \\
\text { talentos, } \\
\text { destrezas y } \\
\text { competencias }\end{array}$ & $\begin{array}{l}\text { Inversión en } \\
\text { formulación y } \\
\text { desarrollo de } \\
\text { competencias por } \\
\text { empleado } \\
\end{array}$ & & $\begin{array}{l}\text { El personal profesional cuenta con estudios } \\
\text { de postgrado; la inversión que hicieron } \\
\text { durante el presente ejercicio fue de } \\
\text { S/. } 63,452 \text {. }\end{array}$ \\
\hline & $\begin{array}{l}\text { Horas de capacitación } \\
\text { por empleado }\end{array}$ & & $\begin{array}{l}\text { El promedio de horas de capacitación es } \\
\text { de } 200\end{array}$ \\
\hline & Número de empleados & & $\begin{array}{l}\text { Actualmente se cuenta con un personal de } \\
257 \text { personas entre empleados y obreros. }\end{array}$ \\
\hline & Ventas por empleado & & La venta por empleados es de S/. 56,280 \\
\hline Eficiencia & $\begin{array}{l}\text { Valor agregado por } \\
\text { empleado }\end{array}$ & & Se estima un valor agregado de $S / .10,130$ \\
\hline & $\begin{array}{l}\text { Beneficios totales } \\
\text { sobre N.0 de } \\
\text { empleados } \\
\end{array}$ & & La relación es de 7,793 \\
\hline $\begin{array}{l}\text { Retención del } \\
\text { personal }\end{array}$ & $\begin{array}{l}\text { Indice de satisfacción } \\
\text { de empleados } \\
\text { según encuesta (i) }\end{array}$ & & $\begin{array}{l}\text { La satisfacción de los empleados es de } \\
72 \% \text { debido a la capacitación y al } \\
\text { programa de incentivos. }\end{array}$ \\
\hline & Rotación de empleados & & $\begin{array}{l}\text { La rotación de empleados es de } 2 \text { personas } \\
\text { por cada } 10 \text {. }\end{array}$ \\
\hline & $\begin{array}{l}\text { Inversión en } \\
\text { capacitación en nuevas } \\
\text { tecnologías y métodos } \\
\text { de trabajo }\end{array}$ & $\begin{array}{l}\text { Se invirtió } 88,460 \text { para adquirir nuevos equipos } \\
\text { y software para mejorar la producción }\end{array}$ & \\
\hline $\begin{array}{l}\text { Calificación del } \\
\text { personal }\end{array}$ & $\begin{array}{l}\text { Porcentaje } \\
\text { profesionales + } \\
\text { técnicos / total } \\
\text { empleados }\end{array}$ & & $\begin{array}{l}\text { El porcentaje de profesionales y técnicas } \\
\text { asciende a } 55 \text {. }\end{array}$ \\
\hline & \begin{tabular}{|l|} 
Nivel de educación \\
promedio del personal
\end{tabular} & & $\begin{array}{l}\text { El } 60 \% \text { del personal entre obreros y } \\
\text { empleados tiene educación técnica y } \\
\text { superior respectivamente. }\end{array}$ \\
\hline & $\begin{array}{l}\text { Gastos capacitación } \\
\text { /total gastos } \\
\text { operativos } \\
\end{array}$ & $\begin{array}{l}\text { La proporción es de } 10,152 \text {, ello debido a los } \\
\text { programas de especialización del staff } \\
\text { administrativo }\end{array}$ & \\
\hline
\end{tabular}




\section{BIBLIOGRAFIA}

BÉRTORA, Héctor Raúl Llave de negocio, Ediciones Macchi López. 1975.

- CHÁVEZ, Osvaldo; PAHLEN ACUÑA, Ricardo. Valor llave. Un enfoque actual, Ediciones Macchi. 1996

- BOLETÍN ASOCIACIÓN ESPAÑOLA DE CONTABILIDAD Y AUDITORIA N. ${ }^{\circ}$ 50. Entrevista a Leandro Cañibano. "Nuevos desafios de la contabilidad ante el siglo XXI".

- SIERRA FERNÁNDEZ, Monserrat. "¿Hacia una nueva contabilidad?. Contabilidad del Capital Intelectual, Boletín de la Asociación Española de Contabilidad y Auditoría N. ${ }^{\circ} 49$.
- INTERNATIONAL FEDERATION OF ACCOUNTANTS. ESTUDIO 7: The measurement and management of Intellectual Capital: An introduction. EEUU. Septiembre de 1998.

- CAÑIBANO, Leandro; GARCÍA-AYUSO COVARSI, Manuel; SÁNCHEZ, Paloma. $L$ a relevancia de los intangibles para la valoración y la gestión de empresas: revisión de literatura. Asociación Española de Contabilidad y Auditoria. Madrid, 1999.

- CARAZAY, Cristina; FERNÁNDEZ, Analía; NANNINI, María Susana; SUARDI, Diana. "La llave de negocios en los Estados Contables». Revista Desarrollo y Gestión N. ${ }^{\circ} 10$ Julio, 2000. 